\title{
Appendix IV: Personal Identity Essay
}

Directions: Commonly, the term "literacy" is used to refer to reading and writing abilities. Here, however, we more broadly conceive of the term as awareness and understanding of communication relevant to a specific situation or context. For this assignment, your "literate practices" are defined as your ability to recognize, learn about, analyze and/or communicate matters related to the many facets of natural disasters. To focus your essay, choose a specific situation or focal event that illustrates how you learned about, participated in, and/or analyzed behavior related to some aspect of your identity, keeping in mind that this may encompass a variety of experiences.

As is common with narratives, your essay should make use of a subtle thesis that establishes the significance of the focal event as opposed to stating the thesis at the end of the first paragraph or announcing it as the "moral of the story" in the narrative's final paragraph. Be aware that a subtle thesis does not necessarily occur in one sentence. Furthermore, it should relay the importance of the experience for you and/or for a larger community; thus, you should show your readers, rather than tell them, what new literacy you acquired.

Personal Identity and Personal Literacy Essay Genres: The term literacy has traditionally been used to refer to reading and writing, but literacy can be used to characterize a broad range of abilities or practices that allow people to act effectively within various environments. For this essay, you should write a personal identity narrative that 1 ) tells the story of a particular experience or event about their literate practices relevant to an aspect of their personal identity, and 2) analyzes these literate practices and the broader implications of their ability to understand and communicate within this context.

An important issue to consider as you are composing and revising your literacy narrative is the value of addressing the significance or implications of the selected focal event. Addressing these implications will involve analytical skills that they will use in future class assignments, your other courses, and in the workplace. The implications of the event that you narrate for this essay could also be for yourself, personally. You might want to ask yourself: How did this event alter you and/or your life? Or, the implications of your focal event could be for humanity in general, prompting such questions as: What does this focal event suggest about your relationship to the world outside of that community? How did your ability to understand this situation affect your ability to negotiate other such situations or within society at large?

Audience: A general academic audience, such as your classmates, interested in your story and background. Proceed as though you are telling your classmates a story rather than composing a traditional, formal essay.

Point of view: You can utilize the first-person point of view.

Word Count: 1,000 words (approximately 4 pages) 
Sources: No sources are necessary for this shorter writing.

Note: Keep in mind that you are not expected to (nor should you) divulge sensitive and/or private information about yourself or someone else. The general topic-some aspect of your identity-is broad enough for you to select a focus that would be appropriate for an audience of your class peers and instructor. If you have questions about the appropriateness of your focus, please consult your instructor.

Grading Criteria for the Personal Identity Essay

Students writing competent Personal Identity Essays should fulfill the following requirements:

- Demonstrate a satisfactory ability to complete the essay, as you undergo the process of evaluating your essay issue or topic, investigating it further via writing, and then drafting, revising, and editing to create a final product.

- Present a satisfactory genre example of the Personal Identity Essay that explores an event that exemplifies your literate practices relevant to some aspect of your identity.

- Demonstrate a satisfactory understanding of how to construct an essay that features a descriptive organizational thesis and focused, organized paragraphs. The narrative should have a thesis that addresses the importance of this literacy event either for you personally or for people generally. Ideally, this thesis should be subtly developed (rather than explicitly stated).

- Have a title and an introductory paragraph that promote interest.

- Have effective transitions (between sentences, paragraphs, and larger sections).

- Offer, in a satisfactory manner, supporting proof or claims to back up general, abstract premises, present a balance of both textual summary and analysis. The narrative should support claims about your literacy through vivid description and analysis of the focal event, the activity you took part in, and the people involved.

- Conform satisfactorily with MLA standards in formatting the paper.

- Demonstrate a satisfactory ability to utilize stylistic principles meant to hook and hold the reader's interest, including variety in language and syntax use.

- Demonstrate a satisfactory ability to write using Standard American English. While essays deemed average may suffer from one or two egregious errors and/or several less offensive errors, the kinds and numbers of errors should not undermine readers' ability to comprehend and interact with the content. Pay particular attention to the following:

-pronoun clarity

-gender inclusive language

-precise language

-punctuation

Citation Note: The prompts utilize some ideas and text from curriculum from created by the Writing Studies Office at Southern Illinois University. 